\title{
An Examination of the Fragmentation Rules in Organic Mass Spectrometry by MO Methods. I.
}

\author{
Ethylamine as a Model Compound for the $a$-Cleavage
}

\author{
Hideyuki Konishi* and Hisao Nakata*
}

(Received 15 August 1977)

\begin{abstract}
The electronic structures of ethylamine and the related species have been calculated by means of the INDO method to examine the scope and limitations of the so-called fragmentation rules in organic mass spectrometry. Both the unpaired electron in the molecular ion and stabilization by the conjugation in the reaction transition state are confirmed to play important roles in fragmentation reactions. Localized MO representation of the reaction transition states and applicability of bond indices are also discussed.
\end{abstract}

\section{Introduction}

The electronic structures of ethylamine have been discussed by several research groups in relation to the fragmentation mechanism in mass spectrometry. Thus, Lorquet et al.1,2) calculated the potential energy surface and the electron distributions by means of variants of the extended Hückel and the CNDO methods. The calculated reaction paths corresponding to the fragmentations are not sufficiently correlated to the experiments, but the sensitivity of the charge distribution to the molecular geometry is stressed to criticize the "mechanistic" interpretation approach. Hirota et al.3) also discussed the fragmentation probability with the aid of the electron distri- bution of the highest occupied molecular orbital in the neutral molecule. In our opinion, the basic assumptions of their theory still leave some ambiguity, and assumed electronically excited species are needed to be confirmed by experiments. On the other hand, Ikuta et al.4) employed the fragment ionization process, but more detailed discussions of this process are inevitably required. Recently, Ichikawa and Ogata5,6) gave attention to the electronic structures of the ground state molecular ion and obtained the potential energy curves for the $\mathrm{C}-\mathrm{C}$ and $\mathrm{C}-\mathrm{N}$ dissociations which seem to be satisfactorily consistent with the experimental activation energy profiles within the semiempirical MO framework.

On recognizing the fragmentation of 
organic molecules in a mass spectrometer as consecutive unimolecular reactions of ionized molecules, we encounter the idea whether the reactions occur in the electronically excited states or not. Although the assumption that the reactions take place in the ground state is not assured generally for organic molecules, it may be acceptable in explaining the dominant parts of mass spectral fragmentations.7) Therefore, ionized ethylamine in its electronically ground state is considered as an objective in the present paper.

Mechanistic interpretations are usually based on each formal and/or canonical structures of the molecular ion in the valence bond representation which are not always individually realistic. Thus, the well approximated electronic structures of ionized molecule by means of MO methods are necessary to examine the concept of "charge localization", where the role of the positive charge is overestimated apart from that of the unpaired electron.8) The successive study of the electronic structures of the ionized molecule along the reaction path will reveal the functions of both the positive charge and the unpaired electron. Such an elaborate work connected with the fragmen. tation rules in organic mass spectrometry would advance the present status of mechanistic approach beyond the "charge localization", which some authors called a vague theory. ${ }^{8)}$

In the present paper, we will examine by the semi-empirical MO methods the scope and limitations of the so-called fragmentation rules, particularly in attempting to clarify whether the positive charge and the unpaired electron play an important role in an $\alpha$-cleavage reaction. As model compounds, we have selected four related species, i.e., $\mathrm{C}_{2} \mathrm{H}_{5} \mathrm{NH}_{2}, \mathrm{C}_{2} \mathrm{H}_{5} \mathrm{NH}_{2}+, \mathrm{C}_{2} \mathrm{H}_{5} \mathrm{NH}$, and $\mathrm{C}_{2} \mathrm{H}_{5} \mathrm{NH}_{3}{ }^{+}$.

\section{Theoretical}

Basic MO wavefunctions in the present treatment are obtained by means of the INDO method which is more suitable than the CNDO method for open-shell molecules because of the spin correlation.9) The unristricted Hartree-Fock procedure 10) which does not satisfy the eigenvalue problem of $\mathrm{S}^{2}$ is reinforced with the aid of the annihilation refinement for the description of spin densities. 11)

Localized molecular orbitals (LMO's) transferred from the canonical SCF MO's have been proved useful in allowing intuitive ideas of chemical bonding.12) Therefore the change of the LMO's of ionized molecules along the reaction path could offer a distinct feature of the chemical bonds during the fragmentation reactions in mass spectrometry. The LMO's of open-shell molecules are obtained separately within the same spin orbitals on the basis of the energy localization method. 12)

To discuss the problems concerning either bond energies or the change of bond lengths in molecules, the total energy ( $\mathrm{E}^{\text {total }}$ ) is defined as the sum of the electronic energy ( $E^{\text {elec }}$. $)$ and the core repulsion energy ( $\left.\mathrm{E}^{\text {core }}\right)$ in semi-empirical MO methods for valence electron systems such as in the INDO method.

$$
\mathrm{E}^{\text {total }}=\mathrm{E}^{\text {elec. }}+\mathrm{E}^{\text {core }}
$$

$\mathrm{E}^{\text {elec. }}$ is represented as 
An Examination of the Fragmentation Rules in Organic Mass Spectrometry by MO Methods. I.

$$
\mathrm{E}^{e l e c .}=\frac{1}{2} \sum_{r} \sum_{s} \mathrm{P}_{r s}\left(\mathrm{H}_{r s}+\mathrm{F}_{r s}\right)
$$

where $\sum_{r}$ denotes the summation over all valence AO's considered, and $\mathrm{P}_{r s}, \mathrm{H}_{r s}$ and $\mathrm{F}_{r s}$ are, respectively, the bond order, the core-resonance integral, and the Fock's operator between the $r$-th and $s$-th AO's. $E^{c o r e}$ is evaluated by a point-charge model as

$$
\mathrm{E}^{\text {core }}=\sum_{A}>\sum_{B} Z_{A} Z_{B} \mathrm{e}^{2} / \mathrm{R}_{A B}
$$

where $Z_{A}$ is the core charge of atom $A$ and $\mathrm{R}_{A B}$ is the internuclear distance between atoms $A$ and $B$. Within the approximation of the INDO method which neglects consequently the three- and four-center terms, $E^{\text {total }}$ can be written as the sum of the monoatomic part $\left(\mathrm{E}_{A}\right)$ and the diatomic part $\left(\mathrm{E}_{A B}\right)^{9)}$.

$$
\mathrm{E}^{\text {totat }}=\sum_{A} \mathrm{E}_{A}+\sum_{A}>\sum_{B} \mathrm{E}_{A B}
$$

The term $\mathrm{E}_{1 B}$ was empirically connected with the bond length ${ }^{13}$ ) and was shown to be a measure of the strength of the chemical bond. 14, 15)
The more logical quantity corresponding to the bond energy has been asked for. 16) Hirao has recently presented a model defining the bond energy based on LMO's 17). According to the modified SCF operator method 18), $E^{\text {elec. }}$ is a simple sum of the modified orbital energies $\left(\mathrm{E}_{i}^{\text {elec. }}\right.$ ).

$$
\mathrm{E}^{e l e c .}=\sum_{i} \mathrm{E}_{i}^{e l e c}
$$

Replacing the sums over distinct cores by sums over bond pair cores in the equation of the $\mathrm{E}^{\text {core }}$,19) one obtains

$$
\mathrm{E}^{\text {core }}=\sum_{i} \mathrm{E}_{i}^{\text {core }}
$$

On the definition of the bond energy $\left(\mathrm{B}_{i}\right)$,

$$
\mathrm{B}_{i}=\mathrm{E}_{i}^{e l e c .}+\mathrm{E}_{i}^{\text {core }}
$$

the total energy is expressed quite rigorously as a sum of bond energies.

$$
\mathrm{E}^{\text {total }}=\sum_{i} \mathrm{~B}_{i}
$$

To discriminate the role of the positive charge and that of the unpaired electron in fragmentation mechanisms, ethyl amino

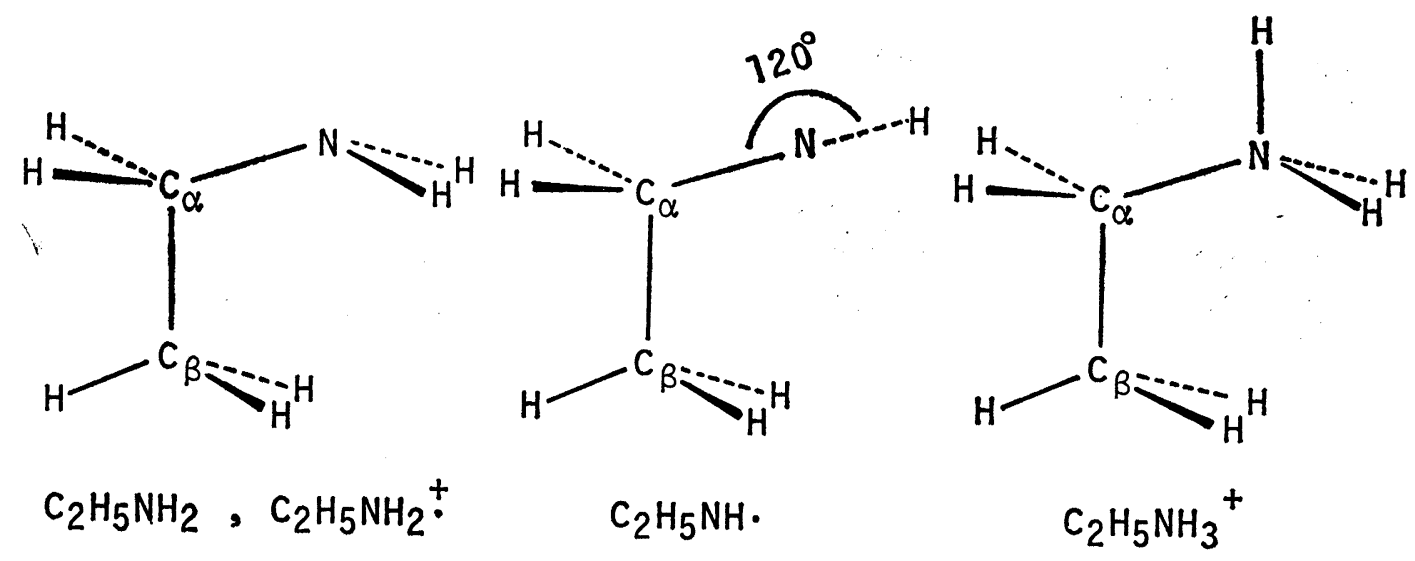

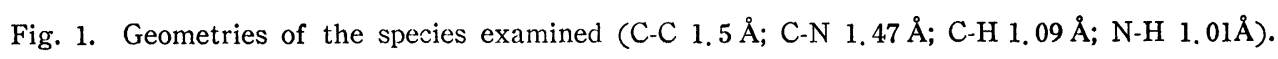


radical $\left(\mathrm{C}_{2} \mathrm{H}_{5} \mathrm{NH} \cdot\right)$ and ethyl ammonium ion $\left(\mathrm{C}_{2} \mathrm{H}_{5} \mathrm{NH}_{3}{ }^{+}\right)$are adopted in this calculation besides ethylamine and ionized ethylamine $\left(\mathrm{C}_{2} \mathrm{H}_{5} \mathrm{NH}_{2}^{+}\right)$. For the geometry of these species, the lengths of the same kind of bonds are set to be equal as given in Fig. 1 and the hybridization of both carbon and nitrogen atoms is uniformly taken to be tetrahedral except for the nitrogen atom in $\mathrm{C}_{2} \mathrm{H}_{5} \mathrm{NH}$. where $\mathrm{sp}^{2}$ hybridization is assumed. Further the lengths of the C-C and $\mathrm{C}-\mathrm{N}$ bonds are varied separately keeping the other internuclear distances and angles at a fixed value.

\section{Results and Discussions}

\section{3-1. Potential Energy Curves}

The potential energy surfaces calculated with the semi-empirical MO methods are not always reliable, and it is difficult to discuss the energy differences between the $\mathrm{C}-\mathrm{C}$ and $\mathrm{C}-\mathrm{N}$ bonds during their cleavage reactions. ${ }^{2)}$ However, even in these approximations, it is usually possible to compare the relative quantities of the same kind of bonds. We therefore refer to the energy problem only for the comparative feature of the C-C bond among the species.

Potential energy curves for the C-C dissociation reaction of ethylamine and the related species, obtained by keeping the other bond distances and angles unchanged, give too much activation energies than those actually observed (Fig. 2). However, the geometries fitted to have the least energies in each species may not result the change of order of the curves. The four curves which lie side by side without crossing are therefore assumed to repre-

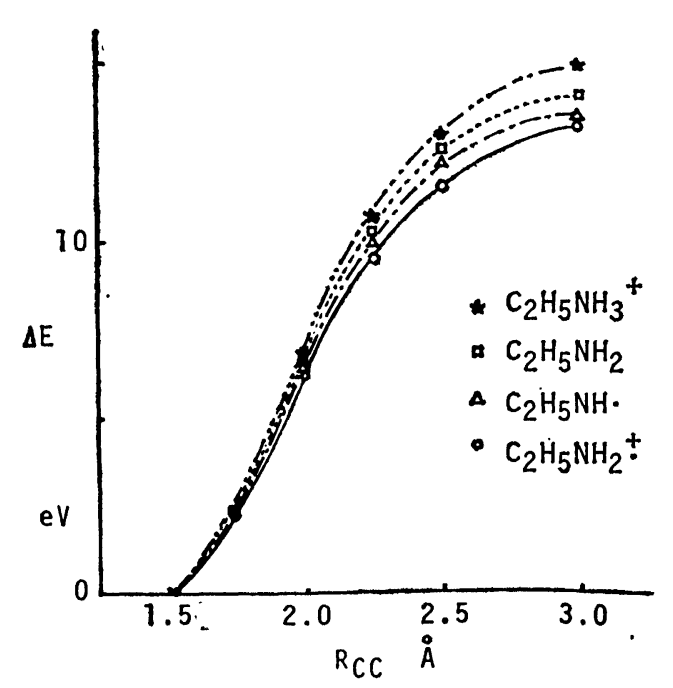

Fig. 2. Potential energy curves corresponding to C-C stretching.

sent the relative amounts of the activation energies.

A characteristic feature of the ionized ethylamine is the possession of both the unpaired electron and the positive charge compared with the neutral ethylamine. From Fig. 2 and the following reactions, we first

$$
\begin{aligned}
& \mathrm{C}_{2} \mathrm{H}_{5} \mathrm{NH}_{3}{ }^{+} \longrightarrow \mathrm{CH}_{3} \cdot+\mathrm{CH}_{2} \mathrm{NH}_{3}{ }^{+} \\
& \mathrm{C}_{2} \mathrm{H}_{5} \mathrm{NH}_{2} \longrightarrow \mathrm{CH}_{3} \cdot+\mathrm{CH}_{2} \mathrm{NH}_{2} \\
& \mathrm{C}_{2} \mathrm{H}_{5} \mathrm{NH} \cdot \longrightarrow \mathrm{CH}_{3} \cdot+\mathrm{CH}_{2}=\mathrm{NH} \\
& \mathrm{C}_{2} \mathrm{H}_{5} \mathrm{NH}_{2}+\longrightarrow \mathrm{CH}_{3} \cdot+\mathrm{CH}_{2}=\mathrm{NH}_{2}{ }^{+}
\end{aligned}
$$

point out that the starting parent species including the unpaired electron proceed with lower activation energies than those excluding it. Since these reactions involve homolytic cleavages of the C-C bond, the initial unpaired electron seems to facilitate the process on making a new electron pair with simultaneous rupture of the other bond. On the other hand, it is more complicated to declare the general trend for the effect of the positive charge.

Contributions of the unpaired electron 
An Examination of the Fragmentation Rules in Organic Mass Spectometry by MO Methods. I.

and the positive charge for lowering the activation energy can be evaluated qualitatively in the following manner. The difference of the energy between $\mathrm{C}_{2} \mathrm{H}_{5} \mathrm{NH}_{2}$ and $\mathrm{C}_{2} \mathrm{H}_{5} \mathrm{NH}$. is attributed to the unpaired electron and that between $\mathrm{C}_{2} \mathrm{H}_{5} \mathrm{NH} \cdot$ and $\mathrm{C}_{2} \mathrm{H}_{5} \mathrm{NH}_{2}+$ is ascribed to the positive charge. The positive charge in $\mathrm{C}_{2} \mathrm{H}_{5} \mathrm{NH}_{2}^{+}$seems to play the same role in facilitating the reaction as the unpaired electron, but it is not the case for $\mathrm{C}_{2} \mathrm{H}_{5} \mathrm{NH}_{3}{ }^{+}$. This contrasted effect of the positive charge may be explicable by the bonding character of product ions and reaction transition states. Thus, immonium ion $\left.\left(\mathrm{CH}_{2}=\mathrm{NH}_{2}{ }^{+}\right)^{2 J}\right)$ and the corresponding transition state have strong $\pi$-type conjugations which appreciably stabilize the both states, while the same conjugations can not be anticipated for both $\cdot \mathrm{CH}_{2} \mathrm{NH}_{3}{ }^{+}$and the corresponding transition state because of the saturation of bonding at the nitrogen atom.

From these results, it seems most reasonable to conclude that the unpaired electron plays an important role in the mass spectral C-C homolytic cleavage of ethylamine. In addition, the conjugative stabilization in transition states and in product ions must also be taken into consideration in order to predict the fragmentation pathways. On the other hand, an accelerating effect of the positive charge in ionized ethylamine seems to be not operative in the homolytic $\mathrm{C}-\mathrm{C}$ cleavage reaction, except for cases where the charge on the atom to be broken may support the heterolytic scission.

\section{3-2. Charge Distributions}

The variation of the charge distribu- tions of $\mathrm{C}_{2} \mathrm{H}_{5} \mathrm{NH}_{2}^{+}$with the $\mathrm{C}-\mathrm{C}$ bond stretching (Fig. 3) is almost the same as that obtained by Krier et al.2) A small difference in absolute values is apparently resulted from the method used. Charge distributions of $\mathrm{C}_{2} \mathrm{H}_{5} \mathrm{NH}_{3}{ }^{+}$are also shown in Fig. 3. Positive charges are seen to be very much delocalized for both ions at the start. A notable increase of the positive charge on the $\alpha$-carbon $\left(\mathrm{C}_{\alpha}\right)$ atom in $\mathrm{C}_{2} \mathrm{H}_{5} \mathrm{NH}_{2}{ }^{+}$accompanied by a complementary decrease on the nitrogen atom is found near the transition state. This means the electron must transfer from the nitrogen atom to the $\alpha$-carbon atom through the $\pi$-type conjugation of the C-N bond, which comes into existence toward the transition state.

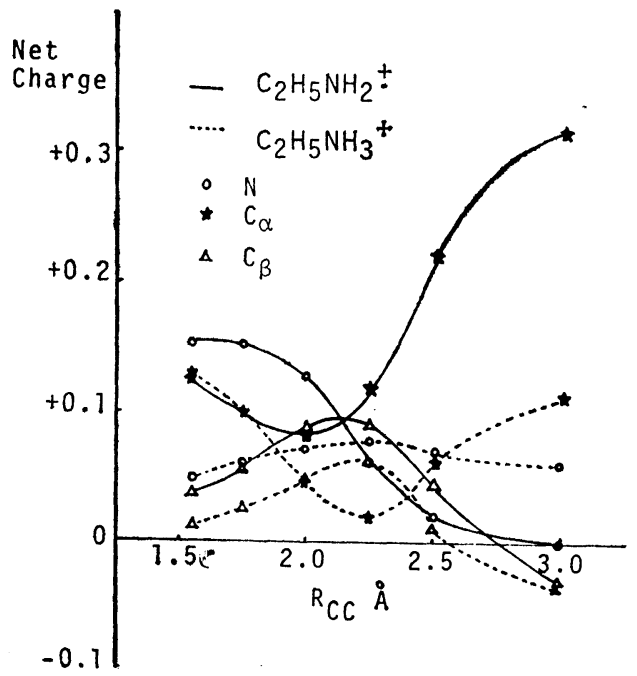

Fig. 3. Net charge distribution corresponding to $\mathrm{C}-\mathrm{C}$ stretching.

\section{3-3. Spin Densities}

The density of the unpaired electron is defined in the UHF theory as spin density which is $\alpha$-spin electron density minus $\beta$-spin electron density. Only a single annihilation 

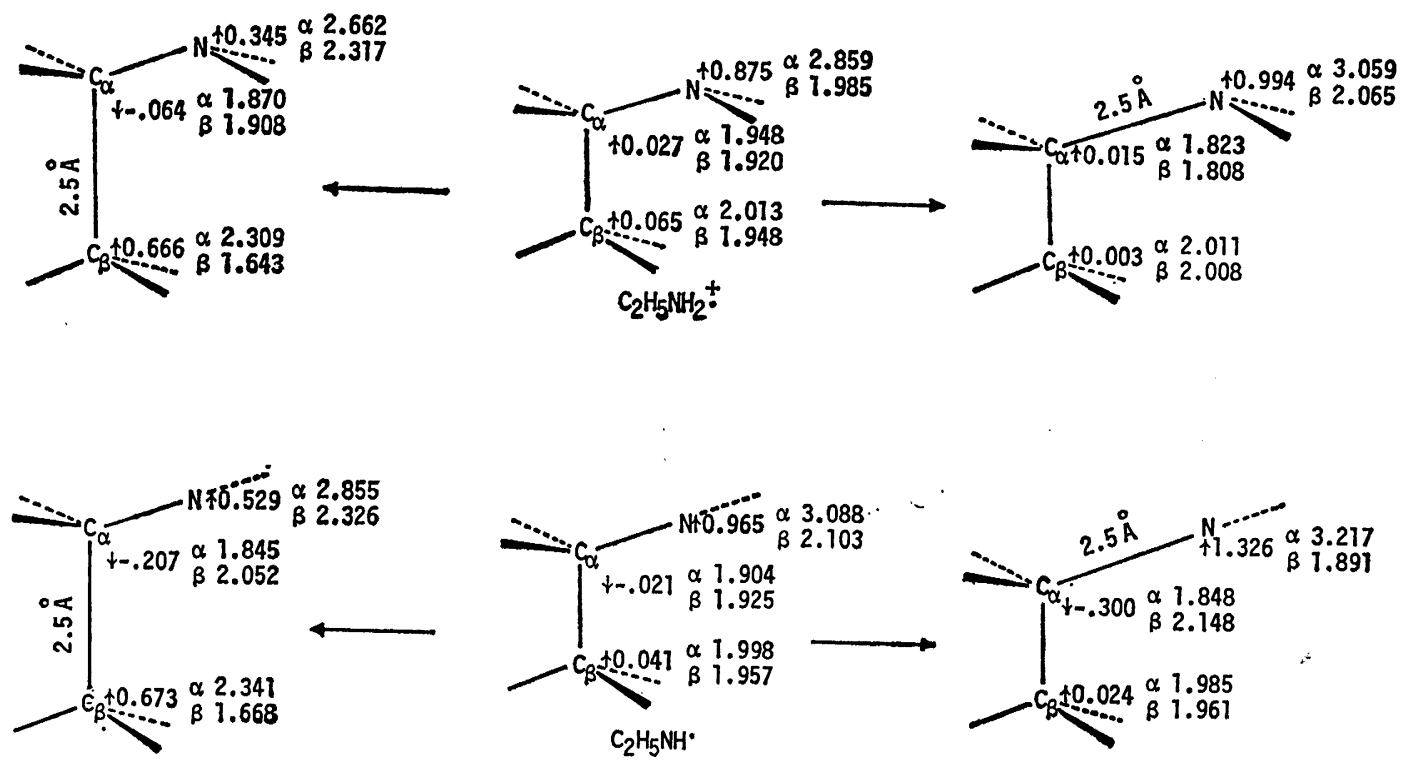

Fig. 4. Distributions of spin density.

refinement demonstrated the improvement of spin density especially in the transition state region, e.g., the spin density at the nitrogen atom in $\mathrm{C}_{2} \mathrm{H}_{5} \mathrm{NH}_{2}+$ with the $\mathrm{C}-\mathrm{C}$ bond stretching until $2.5 \AA$ was reduced from 0.513 to 0.345 (Fig. 4).

Spin densities together with $\alpha$ - and $\beta$ spin electron densities for $\mathrm{C}_{2} \mathrm{H}_{5} \mathrm{NH}_{2}+$ and $\mathrm{C}_{2} \mathrm{H}_{5} \mathrm{NH}$. are represented in Fig. 4. The atom with largest spin density in $\mathrm{C}_{2} \mathrm{H}_{5} \mathrm{NH}_{2}{ }^{+}$ is varied from the nitrogen atom to the $\beta$ carbon $\left(\mathrm{C}_{\beta}\right)$ atom along the path of the $\mathrm{C}-\mathrm{C}$ bond cleavage reaction. The decrease of spin density at the nitrogen atom is attributed to the increase of $\beta$-spin electron density rather than to the decrease of $\alpha$ spin electron density, while the increase of spin density at the $\beta$-carbon atom is resulted from almost the same contribution of both the increase in $\alpha$-spin and the decrease in $\beta$-spin. This demonstrates the transfer of the pair of electron spins from the nitrogen atom to the $\beta$-carbon atom during the homolytic C-C dissociation, which rationalizes the well-accepted fishhook representation of an $\alpha$-cleavage reaction in ethylamine. This behavior of electron spins is contrasted with that of the heterolytic C-N fission where the spin density remains at the nitrogen atom because the paired electrons move together.

The spin density distribution in $\mathrm{C}_{2} \mathrm{H}_{5}$ NH. exhibits the same trend as in $\mathrm{C}_{2} \mathrm{H}_{5}$ $\mathrm{NH}_{2} \div$ for the $\mathrm{C}-\mathrm{C}$ bond stretching, and also suggests the formation of $\mathrm{C}_{2} \mathrm{H}_{5}$. and $\mathrm{NH}$. (biradical) for the $\mathrm{C}-\mathrm{N}$ stretching. The negative spin density in the $\alpha$-carbon atom corresponding to the excess $\beta$-spin electron may be attributed to the lack of the positive charge in $\mathrm{C}_{2} \mathrm{H}_{5} \mathrm{NH}$. species. 
An Examination of the Fragmentation Rules in Organic Mass Spectrometry by MO Methods. I.

Table 1. LMO eigenvectors

\begin{tabular}{|c|c|c|c|c|c|c|c|c|c|c|c|}
\hline & & & & $\mathrm{N}$ & & & $\mathrm{C}_{\alpha}$ & & & $\mathrm{C}_{\beta}$ & \\
\hline & & & s & $\mathrm{x}$ & $\mathrm{y}$ & $\mathrm{s}$ & $\mathrm{x}$ & $\mathrm{y}$ & s & $\mathrm{x}$ & $\mathrm{y}$ \\
\hline & $\mathrm{C}-\mathrm{C}$ & & .008 & .008 & .003 & .372 & -.007 & -.593 & .375 & -.006 & .607 \\
\hline $\mathrm{C}_{2} \mathrm{H}_{5} \mathrm{NH}_{2}$ & C-N & & .376 & -.585 & -.254 & .329 & .547 & .195 & -.000 & -.007 & .044 \\
\hline & $\mathrm{N}:$ & & .559 & .015 & .824 & .004 & -.010 & .068 & .000 & .030 & -.019 \\
\hline & & $\alpha$ & .007 & .006 & -.000 & .390 & .014 & -.614 & .350 & .002 & .590 \\
\hline & & $\beta$ & -.059 & -.015 & -.274 & .410 & .082 & -.595 & .306 & .025 & .545 \\
\hline $\mathrm{C}_{2} \mathrm{H}_{5} \mathrm{NH}_{2}^{+}$ & $\mathrm{C}-\mathrm{N}$ & $\alpha$ & .411 & -.647 & -.268 & .263 & .488 & .172 & -.005 & .021 & -.001 \\
\hline & & $\beta$ & .491 & -.635 & -.055 & .266 & .480 & .220 & -.009 & .015 & -.017 \\
\hline & $\mathrm{N}$. & $\alpha$ & .549 & .017 & .833 & .005 & .001 & .043 & .019 & -.011 & .024 \\
\hline & C-C & $\alpha$ & .007 & .016 & .058 & .175 & .022 & -.415 & .486 & .001 & .743 \\
\hline $\mathrm{C}_{2} \mathrm{H}_{5} \mathrm{NH}_{2}^{+}$ & 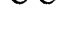 & $\beta$ & -.031 & -.180 & -.595 & .438 & .335 & -.521 & .052 & .005 & .155 \\
\hline $\mathrm{C}-\mathrm{C}$ & $C_{-} \mathrm{N}$ & $\alpha$ & .381 & -.606 & -.293 & .338 & .528 & .092 & .007 & -.003 & .008 \\
\hline $2.5 \AA$ & $0-1$ & $\beta$ & .506 & -.590 & .161 & .187 & .422 & .385 & .019 & -.001 & .062 \\
\hline & $\mathrm{N}$. & $\alpha$ & .547 & -.040 & .801 & -.055 & .001 & .225 & .031 & .052 & -.002 \\
\hline & C-C & $\alpha$ & -.001 & -.001 & .001 & .437 & .117 & -.591 & .332 & .032 & .578 \\
\hline $\mathrm{C}_{2} \mathrm{H}_{5} \mathrm{NH}_{2}^{+}$ & & $\beta$ & -.003 & -.009 & -.019 & $.441^{\circ}$ & .129 & -.588 & .330 & .036 & .577 \\
\hline $\mathrm{C}-\mathrm{N}$ & $C \mathrm{~N}$ & $\alpha$ & .524 & -.716 & -.349 & .092 & .259 & .089 & -.010 & -.020 & -.023 \\
\hline $2.5 \AA$ & $0-1$ & $\beta$ & 656 & -.666 & .197 & .086 & .240 & .088 & -.008 & -.021 & -.022 \\
\hline & $\mathrm{N}$. & $\alpha$ & .566 & .005 & .824 & -.006 & -.016 & -.001 & .004 & -.001 & .004 \\
\hline
\end{tabular}

\subsection{LMO Description}

LMO's have usually been employed to discuss bond properties in comparison with those of the classical theory of organic chemistry12). When an LMO is well localized around the bond, it is easy to understand the nature of the bond.

The coefficients of LMO's for $\mathrm{C}_{2} \mathrm{H}_{5} \mathrm{NH}_{2}$ and $\mathrm{C}_{2} \mathrm{H}_{5} \mathrm{NH}_{2}+$ are presented in Table 1 . The square of a coefficient indicates the electron distribution of the LMO over the atomic orbital, and hence almost all LMO's are localized around the bonds except for the non-bonding orbitals.

In $\mathrm{C}_{2} \mathrm{H}_{5} \mathrm{NH}_{2}$, the electrons around the $\mathrm{C}-\mathrm{C}$ bond distribute symmetrically, while those around the C-N bond are attracted to the nitrogen atom. The coefficients for $\mathrm{C}_{2} \mathrm{H}_{5} \mathrm{NH}_{2}{ }^{+}$, which are not very different from the corresponding coefficients for $\mathrm{C}_{2} \mathrm{H}_{5} \mathrm{NH}_{2}$, clearly indicated that the ionization occurs on the lone pair orbital of the nitrogen atom keeping the distribution of the other electrons almost unchanged. 


\section{H. Konishi, and H. Nakata}
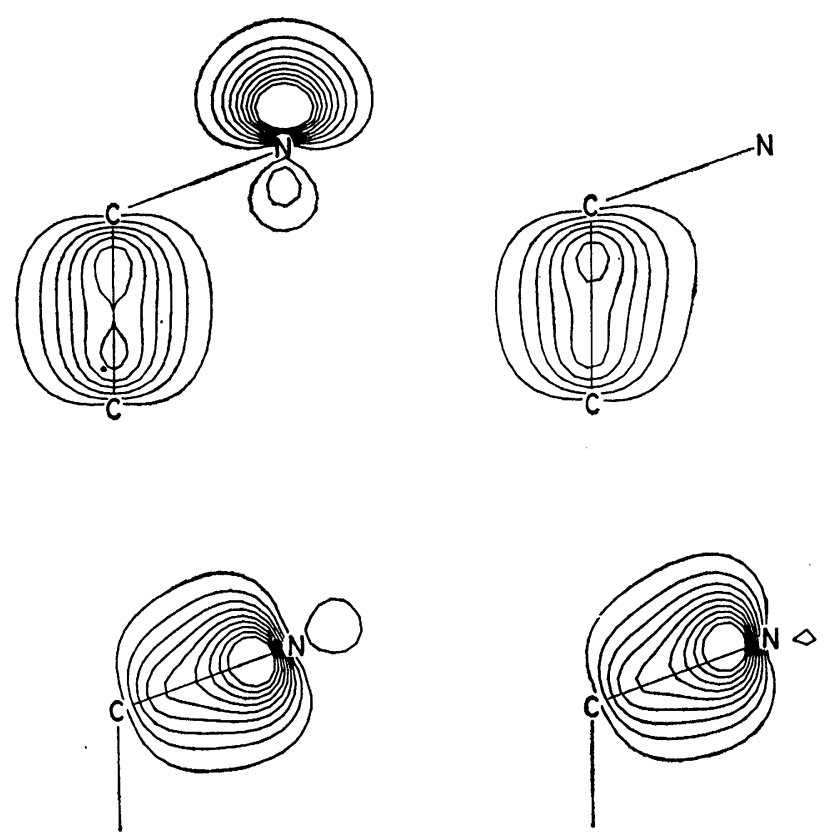

Fig. 5. Electron density maps of LMO's, representing $\alpha$-spin (left) and $\beta$-spin (right) electrons in $\mathrm{C}_{2} \mathrm{H}_{5} \mathrm{NH}_{2}{ }^{+}$. Contours are drawn at every 0.03 electrons/au ${ }^{3}$, starting from 0.03 electrons $/ \mathrm{au}^{3}$, where $1 \mathrm{au}=0.529 \AA$.
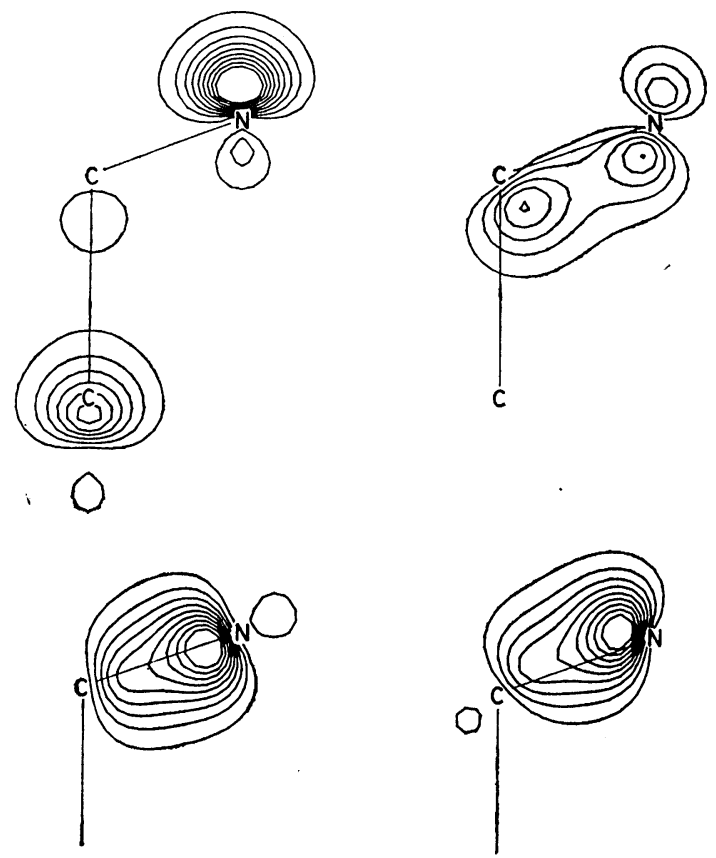

Fig. 6. Electron clensity maps of LMO's, representing $\alpha$-spin (left) and $\beta$-spin (right) electrons in $\mathrm{C}_{2} \mathrm{H}_{5} \mathrm{NH}_{2}{ }^{+}$with the $\mathrm{C}-\mathrm{C}$ bond length of $2.5 \AA$. Contours are drawn as in Fig. 5. 
An Examination of the Fragmentation Rules in Organic Mass Spectrometry by MO Methods. I.

However, the discrepancy between the $\alpha$ - and $\beta$-spin electron distributions can be seen in Fig. 5. The effects of the C-C bond stretching in $\mathrm{C}_{2} \mathrm{H}_{5} \mathrm{NH}_{2}{ }^{+}$are illustrated in Fig. 6. It is shown that the separation between $\alpha$-and $\beta$-spin electron distributions in the homolytic reaction proceeds until the $\alpha$-spin electron localizes on the $\beta$-carbon atom and the $\beta$-spin electron distributes around the C-N bond to make a $\pi$-type conjugation.

From the coefficients for $\mathrm{C}_{2} \mathrm{H}_{5} \mathrm{NH}_{2}+$ with the C-N bond stretched (Table 1), the splitting of spins is scarcely found for both the C.C and C-N bonds correlated to the heterolytic fission. Throughout the Table 1, the non-bonding electrons are well localized on the nitrogen atom and keep their distributions unchanged from the disturbance by the ionization and the bond scission.

\subsection{Bond Indices, $\mathrm{B}_{i}$ and $\mathrm{E}_{A B}$}

The values of $\mathrm{B}_{i}$ and $\mathrm{E}_{A B}$ defined in the previous section are given in Table 2, where the smaller value corresponds to the stronger bond. When we discuss the fragmentation reactions on the basis of the bond strength of the molecular ion, the index $\mathrm{B}_{i}$ may better correlate to the fission probability than the index $\mathrm{E}_{A B}$. For $\mathrm{C}_{2} \mathrm{H}_{5} \mathrm{NH}_{2}$ and $\mathrm{C}_{2} \mathrm{H}_{5} \mathrm{NH}_{2}^{+}$, the values of $\mathrm{E}_{A B}$ suggest that the $\mathrm{C}-\mathrm{C}$ bond is stronger than the $\mathrm{C}-\mathrm{N}$ bond, while the values of $\mathrm{B}_{i}$ indicate the reverse. The tendency to change on ionization is also different for these two indices, i.e., for both the C-C and C-N bonds the $\mathrm{E}_{A B}$ values suggest bond weakening but the $\mathrm{B}_{i}$ values denote bond tightening. These discrepancies may probably arise from whether the index is defined on the rigorous basis or not. Further, the values of $\mathrm{B}_{i}$ for the same kind of bonds do not alter appreciably even in the specified condition such as possession of the positive charge.

In spite of the superiority over the $\mathrm{E}_{A B}$ value, the $\mathrm{B}_{i}$ value is not correlated straightforward to the fragmentation probability. This is because the absolute value of $\mathrm{B}_{i}$ for a given bond represents the hypothetical energy to be required to break that bond without any change at all in other parts of the ion. Actually, slight movement of nuclei and redistribution of electrons along the reaction path would attain the minimum energy strucure that corresponds to the reaction transition state. Therefore, it is obvious that this kind of indices can not predict directly the fission probability in mass spectrometry.6) However, the partial components of the indices such as the

Table 2. Bond indices, $\mathrm{B}_{i}$ and $\mathrm{E}_{\boldsymbol{A B}}$ (in $\mathrm{eV}$ )

\begin{tabular}{|c|c|c|c|c|c|}
\hline & & $\mathrm{C}_{2} \mathrm{H}_{5} \mathrm{NH}_{2}$ & $\mathrm{C}_{2} \mathrm{H}_{5} \mathrm{NH}_{2}+$ & $\mathrm{C}_{2} \mathrm{H}_{5} \mathrm{NH} \cdot$ & $\mathrm{C}_{2} \mathrm{H}_{5} \mathrm{NH}_{3}{ }^{+}$ \\
\hline \multirow{2}{*}{$\mathrm{B}_{i}$} & C-C & -95.33 & -105.05 & -96.28 & -103.46 \\
\hline & $\mathrm{C}-\mathrm{N}$ & -112.70 & -123.77 & -113.51 & -123.60 \\
\hline \multirow{2}{*}{$\mathrm{E}_{A B}$} & $\mathrm{C}-\mathrm{C}$ & -29.46 & -28.22 & -29.05 & -29.46 \\
\hline & $\mathrm{C}-\mathrm{N}$ & -29.19 & -27.79 & -29.75 & -26.34 \\
\hline
\end{tabular}


covalent terms in the $\mathrm{E}_{A B}$ are still useful to discuss qualitatively the nature of bonds because they are regarded in the semiempirical valence electron MO theory as what is bond orders in the Hückel MO theory. ${ }^{13)}$

\section{Conclusion}

As the results of discussion on the electronic structures of ethylamine and the related species by means of the semiempirical MO method, the following con. clusions are obtained.

The unpaired electron in the molecular ion is confirmed to play an important role in the so called $\alpha$-cleavage reaction in mass spectrometry. In addition, stabilization by the conjugation in the reaction transition state which may be correlated with the stability of the products is also an important factor for predicting the fragmentation pathways.

The LMO representation of the reaction transition states demonstrates the change of the conjugation and the transfer mechanism of the unpaired electron during the fragmentation reaction, which rationalizes the usual fishhook formulation of an $\alpha$ cleavage reaction.

Further, an index of the bond energy, $\mathrm{B}_{i}$, which is defined on a fairly rigorous basis, becomes clear to be better than the $\mathrm{E}_{A B}$ value, but still inevitably has limitations to predict the fission probability.

\section{Acknowledgement}

The authors are very grateful to Dr. Kimihiko Hirao for his valuable suggestions about his bond energy concept and for his kind offer of computor programs for this study. They thank K. Ohta and K. Hasegawa for help in some of the calculations. The calculations are carried out on a FACOM 230-60 computor at the Data Processing Center, Nagoya University.

\section{References}

1) J. C. Leclerc and J. C. Lorquet, J. Phys. Chem., 71, 787 (1967).

2) C. Krier, J. C. Lorquet, and A. Berlingin, Org. Mass Spectrom., 8, 387 (1974).

3) K. Hirota, I. Fujita, M. Yamamoto, and Y. Niwa, J. Phys. Chem., 74, 410 (1970).

4.) S. Ikuta, K. Harada, K. Yoshihara, and T. Shiokawa, Mass Spectroscopy (Japan), 22, 239 (1974).

5) H. Ichikawa and M. Ogata, ibid., 21, 91(1973); 23, 157 (1975).

6) H. Ichikawa and M. Ogata, ibid., 23, 299 (1975).

7) B. N. McMaster, in "Mass Spectrometry", Vol. 4, R. A. W. Johnstone ed., Specialist Periodical Reports, The Chemical Society, London (1977), p. 1 .

8) T. W. Bentley, ibid., p. 36.

9) J. A. Pople and D. L. Beveridge, "Approximate Molecular Orbital Theory", McGraw-Hill, New York (1970).

10) J. A. Pople and R. K. Nesbet, J. Chem. Phys., 22, 571 (1954).

11) T. Amos and L. C. Snyder, ibid., 41, 1773 (1964).

12) C. Edmiston and K. Ruedenberg, Rev. Mod. Phys., 34, 457 (1963); J. Chem. Phys., 43, 97 (1965).

13) T. Yonezawa, H. Konishi, and H. Kato, Bull. Chem. Soc. Japan, 41, 1031 (1968); 42, 933 (1969).

14) H. Fischer and H. Kollmar, Theoret. Chim. Acta (Berl.), 16, 163 (1970).

15) S. Ehrenson and S. Seltzer, ibid., 20, 17(1971).

16) See, for a recent example, W. von Niessen, ibid., 38, 9 (1975).

17) K. Hirao, Thesis, Kyoto University, Kyoto (1974).

18) K. Hirao, J. Chem. Phys., 60, 3215 (1974).

19) J. M. Parks and R. G. Parr, ibid., 28, 335 (1958).

20) P. Kollman, J. McKelvey, and P. Gund, $J$. Amer. Chem. Soc., 97, 1640 (1975). 